\title{
Near-maximum-power-point-operation (nMPPO) design of photovoltaic power generation system
}

\author{
B.J. Huang *, F.S. Sun, R.W. Ho \\ Department of Mechanical Engineering, National Taiwan University, Taipei 106, Taiwan, ROC
}

Received 15 April 2003; received in revised form 5 June 2005; accepted 29 June 2005

Available online 25 August 2005

Communicated by: Associate Editor Arturo Morales-Acevedo

\begin{abstract}
The present study proposes a PV system design, called "near-maximum power-point-operation" (nMPPO) that can maintain the performance very close to PV system with MPPT (maximum-power-point tracking) but eliminate hardware of the MPPT. The concept of nMPPO is to match the design of battery bank voltage $V_{\text {set }}$ with the MPP (maximum-power point) of the PV module based on an analysis using meteorological data. Three design methods are used in the present study to determine the optimal $V_{\text {set }}$. The analytical results show that nMPPO is feasible and the optimal $V_{\text {set }}$ falls in the range 13.2-15.0 V for MSX60 PV module. The long-term performance simulation shows that the overall nMPPO efficiency $\eta_{\mathrm{nMPPO}}$ is higher than $94 \%$. Two outdoor field tests were carried out in the present study to verify the design of nMPPO. The test results for a single PV module $(60 \mathrm{Wp})$ indicate that the nMPPO efficiency $\eta_{\mathrm{nMPPO}}$ is mostly higher than $93 \%$ at various PV temperature $T_{\mathrm{pv}}$. Another long-term field test of $1 \mathrm{kWp} \mathrm{PV}$ array using nMPPO shows that the power generation using nMPPO is almost identical with MPPT at various weather conditions and $T_{\mathrm{pv}}$ variation from $24^{\circ} \mathrm{C}$ to $70{ }^{\circ} \mathrm{C}$.
\end{abstract}

(C) 2005 Elsevier Ltd. All rights reserved.

Keywords: MPPT; nMPPO; Meteorological data; PV; Field test; Statistical analysis

\section{Introduction}

A photovoltaic power generation system requires a maximum-power-point tracking (MPPT) to control the photovoltaic arrays to operate at the maximum-power point (MPP) of the PV module in order to obtain the best power generation efficiency. The MPPT can be achieved from a power electronic device that utilizes a DC/DC

\footnotetext{
* Corresponding author. Tel.: +88622362 4790; fax: +8862 23640549.

E-mail address: bjhuang@seed.net.tw (B.J. Huang).
}

converter to adjust the output voltage of the PV array at MPP. Several control schemes were proposed by many researchers, for examples, the step-up methods (Salameh and Taylor, 1990) and the step-down methods (Salameh et al., 1991). The present study proposes a new design concept, called "near-maximum-power-point operation" (nMPPO) that can keep the performance very close to MPPT but eliminate hardware of the MPPT.

Fig. 1 shows the $I-V$ curves measured outdoors using natural sunlight for the PV module MSX-60 (polycrystalline PV) manufactured by Solarex. The $P-V$ curves shown in Fig. 2 reveal that the peak voltages at the maximum-power-points are within a narrow range, 


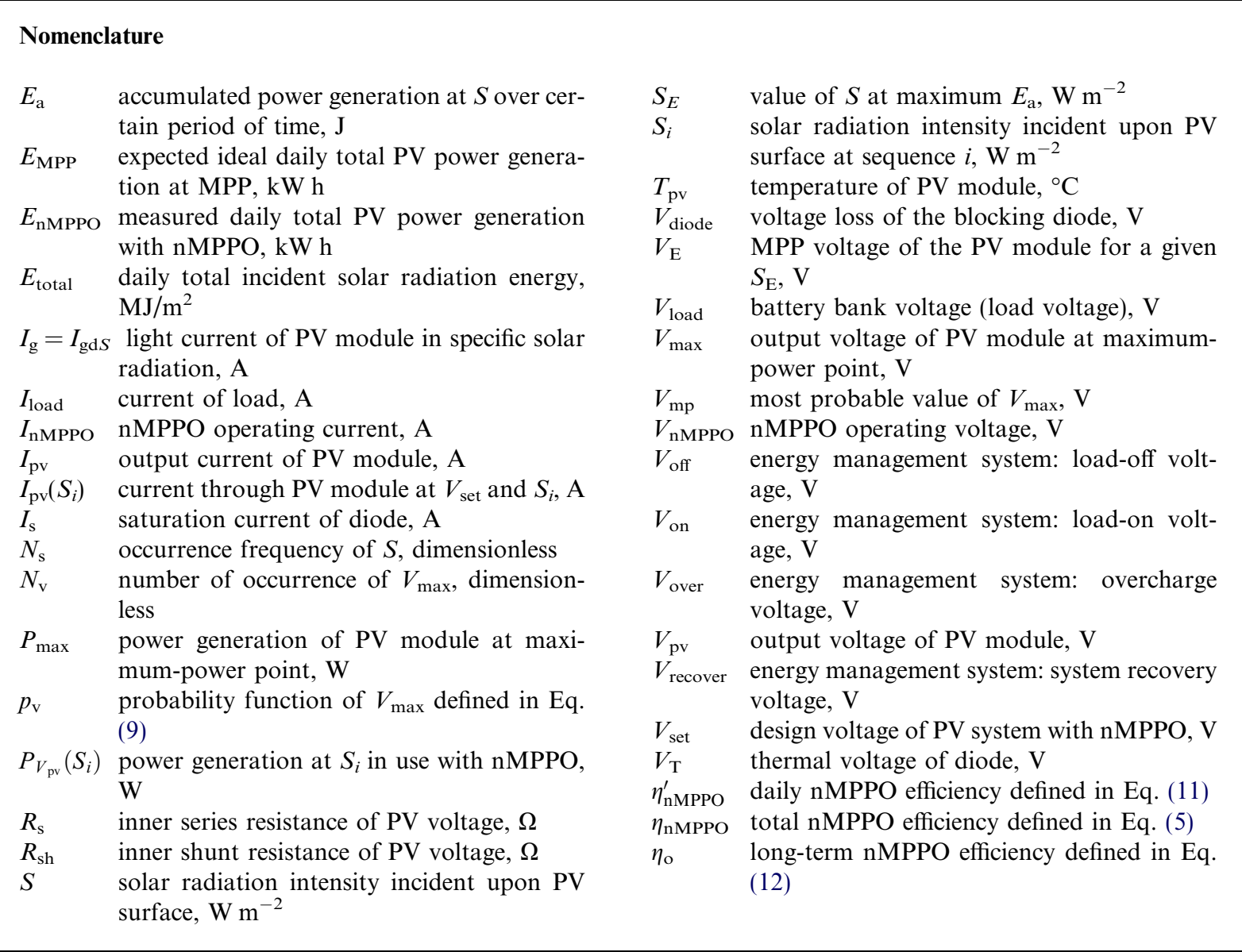

about 14-16 V. Similar phenomenon occurs in many PV modules.

The idea of nMPPO is to use the voltage provided by battery bank to keep the PV at a voltage near the MPP, as shown in Fig. 3. The battery bank has dual functions, i.e., PV voltage control and energy storage. By matching the voltage of battery bank with MPP in design, a PV system with nMPPO can obtain a performance very close to MPPT. Even if the operating point is not exactly the MPP of the PV module, the loss caused by the mismatch will be very small. The problem remained to be solved is how to choose the voltage of the battery bank for an nMPPO. A statistical analysis was carried out in the present study for determining a proper design voltage of battery bank that best matches the PV module under local meteorological condition.

\section{Performance analysis of PV system with nMPPO}

\subsection{Performance of a PV module}

The design of a PV system with nMPPO requires the information of local meteorological data and the perfor- mance curves of the PV module. In the present study, we used Solarex MSX60 as an example. The performance curves of MSX60 are shown in Figs. 1 and 2. They are measured outdoors using natural sunlight. The characteristic equation of the module at a fixed PV temperature $T_{\mathrm{PV}}$ can be expressed as Eq. (1):

$I_{\mathrm{pv}}=I_{\mathrm{gd}} S-I_{\mathrm{s}}\left\{\exp \left[\frac{V_{\mathrm{pv}}+R_{\mathrm{s}} I_{\mathrm{pv}}}{V_{\mathrm{T}}}\right]-1\right\}-\frac{V_{\mathrm{pv}}+R_{\mathrm{s}} I_{\mathrm{pv}}}{R_{\mathrm{sh}}}$.

For MSX60 at $45^{\circ} \mathrm{C}$, the parameters in Eq. (1) are determined experimentally as $I_{\mathrm{gd}}=3.92 \times 10^{-3} \mathrm{~A} \mathrm{~m}^{2} /$ $\mathrm{W} ; \quad I_{\mathrm{s}}=5.25 \times 10^{-11} \mathrm{~A} ; \quad V_{\mathrm{T}}=0.747 \mathrm{~V} ; \quad R_{\mathrm{s}}=1.09 \Omega$; $R_{\mathrm{sh}}=999 \Omega$. The solid lines drawn in Figs. 1 and 2 are based on Eq. (1) using the above parameters. To correct the performance deviation due to temperature change, Eq. (2) is used.

$I_{\mathrm{pv}}=I_{\mathrm{o}}+\alpha\left(T_{\mathrm{pv}}-T_{\mathrm{o}}\right)$,
$V_{\mathrm{pv}}=V_{\mathrm{o}}+\beta\left(T_{\mathrm{pv}}-T_{\mathrm{o}}\right)-R_{\mathrm{s}}\left(I_{\mathrm{pv}}-I_{\mathrm{o}}\right)-K I_{\mathrm{pv}}\left(T_{\mathrm{pv}}-T_{\mathrm{o}}\right)$,

where $I_{\mathrm{pv}}$ and $V_{\mathrm{pv}}$ are the current and voltage of PV module at $\mathrm{PV}$ temperature $T_{\mathrm{pv}}, I_{\mathrm{o}}$ and $V_{\mathrm{o}}$ are the current 


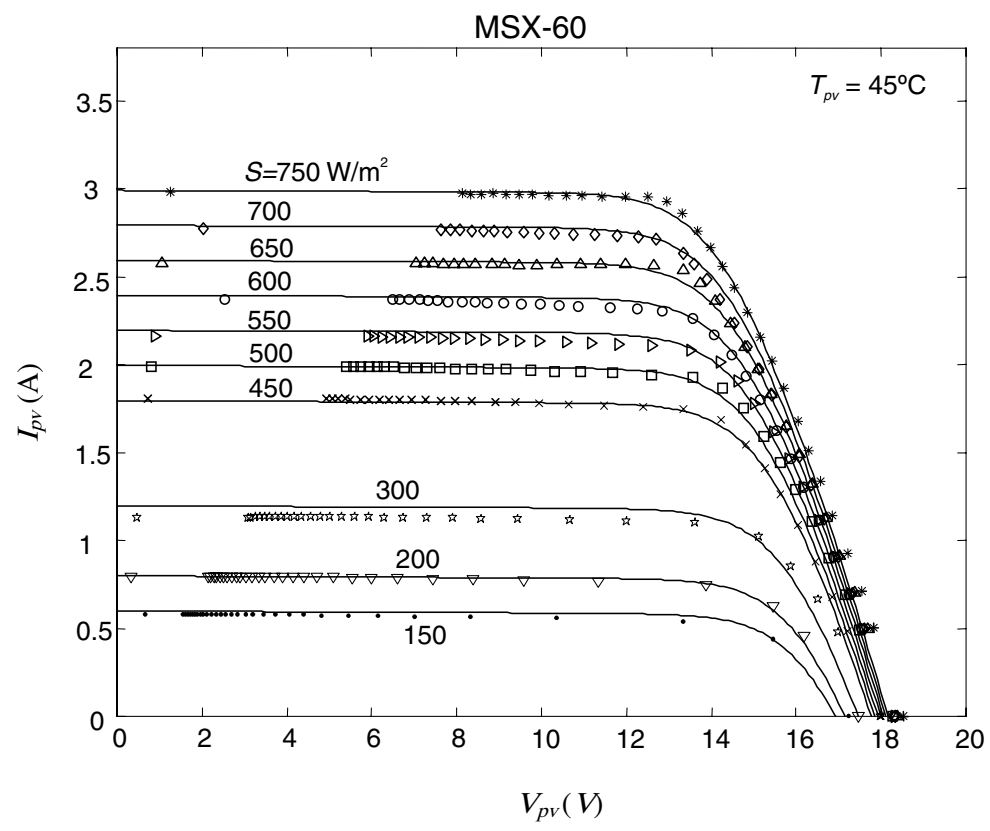

Fig. 1. I-V curves of MSX60.

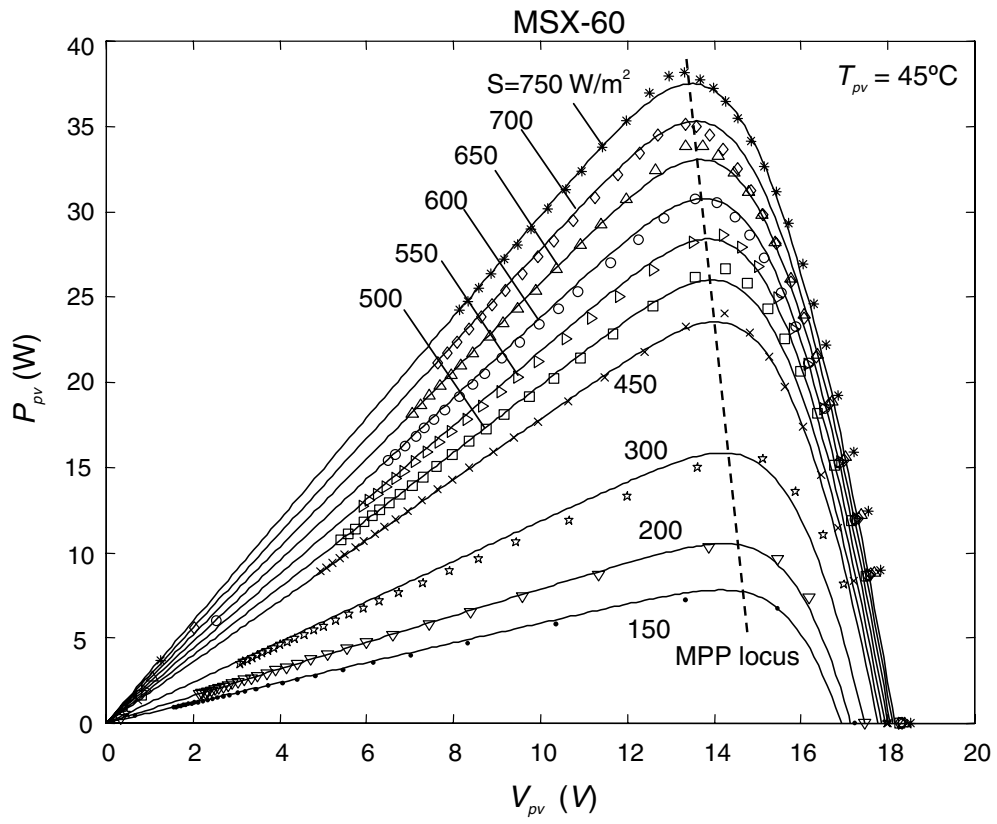

Fig. 2. $P-V$ curve of MSX60.

and voltage of PV module at a reference temperature $T_{\mathrm{o}}$ $\left(45^{\circ} \mathrm{C}\right)$. The coefficients $\alpha, \beta$ and $K$ are determined experimentally and listed in Table 1 . The performance curves of PV module can thus be calculated for any given PV temperature $T_{\mathrm{pv}}$ and solar radiation intensity $S$, using Eqs. (1) and (2).

\subsection{Performance of a PV module at maximum-power} point

Fig. 2 and the performance equations, Eqs. (1) and (2), imply that, for a given solar radiation intensity $(S)$ incident upon the PV module and module temperature 


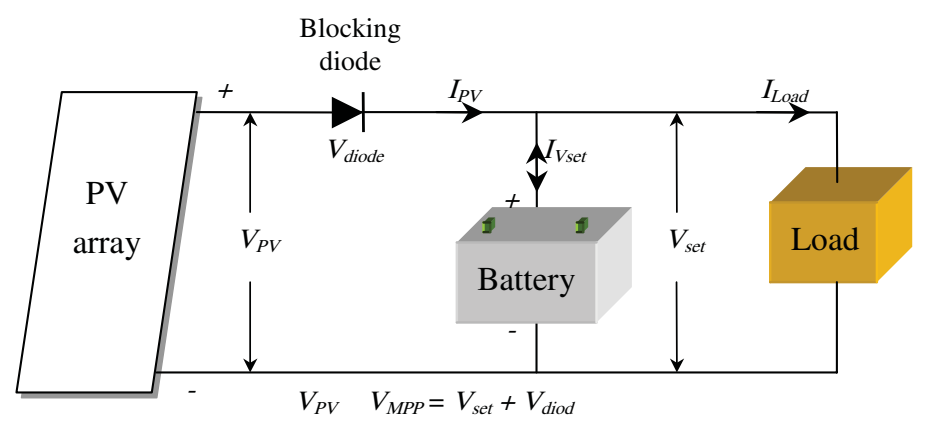

Fig. 3. Schematic diagram of nMPPO $V_{\text {set }}$ design.

Table 1

Temperature coefficients in Eq. (2) for MSX60 PV module

\begin{tabular}{lll}
\hline$\alpha\left(\mathrm{A} /{ }^{\circ} \mathrm{C}\right)$ & $\beta\left(\mathrm{V} /{ }^{\circ} \mathrm{C}\right)$ & $K\left(\Omega /{ }^{\circ} \mathrm{C}\right)$ \\
\hline$-2.24 \times 10^{-3}$ & $-5.51 \times 10^{-2}$ & $6.01 \times 10^{-3}$
\end{tabular}

$T_{\mathrm{pv}}$, there exists an output voltage of the PV module, denoted $V_{\max }$, at which the $\mathrm{PV}$ output power is maximum $P_{\text {max }}$. Using Eqs. (1) and (2), we can calculate the variation of $V_{\max }$ and $P_{\max }$ with $S$ and $T_{\mathrm{pv}}$ and draw the results in Figs. 4 and 5.

\subsection{Statistical analysis of local meteorological data}

An analysis can be carried out to determine the total power generation at various PV output voltage for an
nMPPO. Before doing so, we analyze the occurrence frequency of $S$ using local meteorological data. The top of Fig. 6 is the occurrence frequency of $S$ in Tainan area (southern part of Taiwan) that is based on 15,096 data points of hourly solar radiation intensity from January 1, 1980 to December 31, 1983. The hourly data $S$ has been converted to the value corresponding to solar radiation incident upon a tilted surface of $25^{\circ}$ that is the best installation angle for that area. The statistics used a discrete value of $S$ with $10 \mathrm{~W} / \mathrm{m}^{2}$ increment. Similar calculation was also carried out for Taipei (north part of Taiwan) using 6809 hourly data points for $S>0$ from August 1, 1999 to September 30, 2001, provided by Central Weather Bureau, Taiwan. The results are shown in the bottom of Fig. 6. It is seen that the weather is quite different in these two areas. Tainan is located at latitude

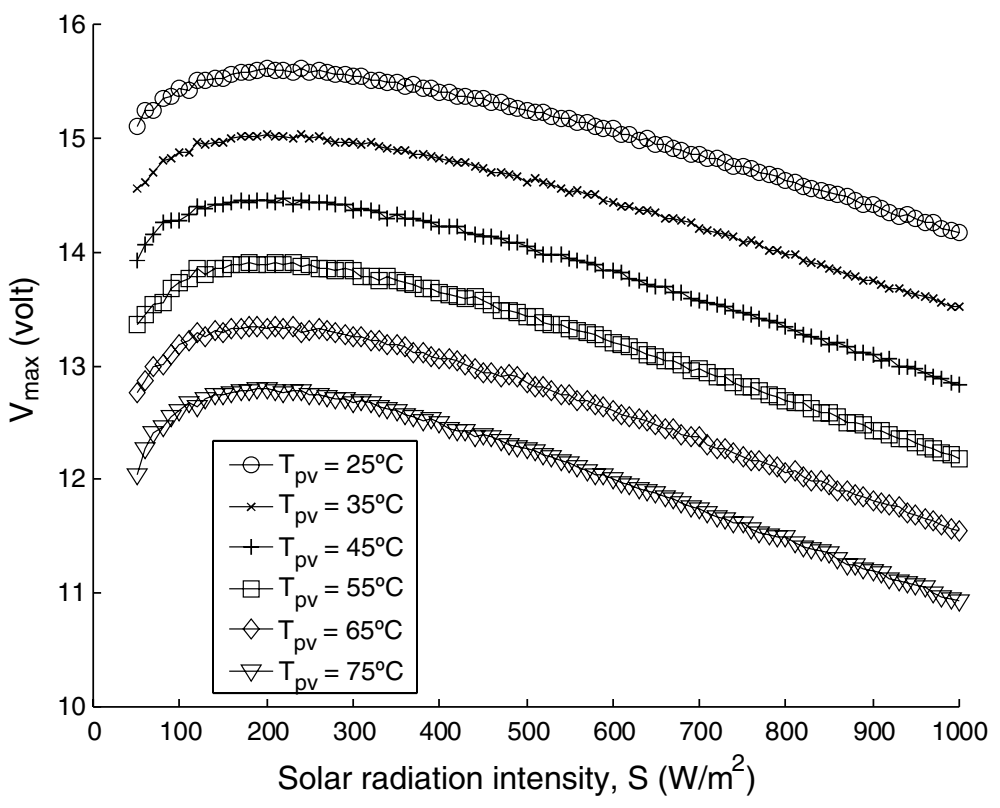

Fig. 4. Variation of $V_{\max }$ with solar radiation intensity $S$. 


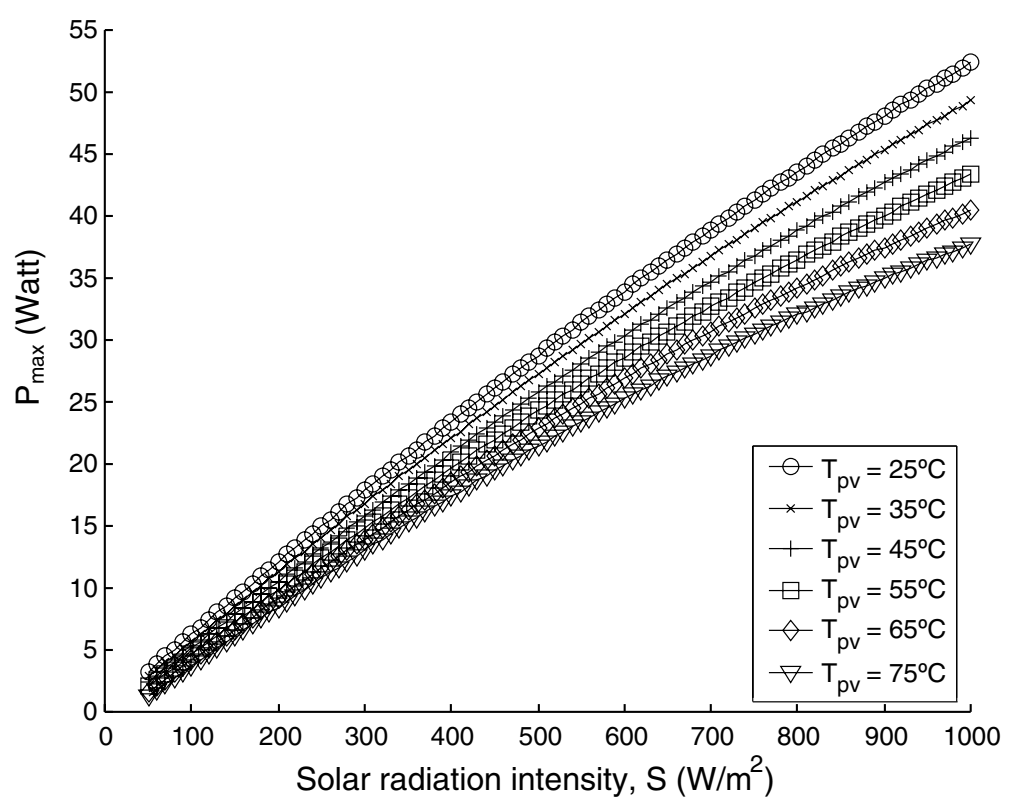

Fig. 5. Variation of $P_{\max }$ with solar radiation intensity S.

$22.5^{\circ}$ that is in tropical region, while Taipei is located at latitude of $25^{\circ}$ that is in subtropical region.

\subsection{Design analysis of a PV system with $n M P P O$ based on local meteorological data}

The output voltage of a PV module at maximumpower point, $V_{\max }$, is the desired operating point of a PV system. The design concept of nMPPO (Fig. 3) is to fix the output voltage of PV module at a value near $V_{\max }$ that can generate a maximum power. However, the output voltage of a PV module at maximum-power point, $V_{\max }$, varies with $S$. A statistical analysis is thus necessary in order to determine an optimum $V_{\text {set }}$ that can generate maximum power. Three design methods are employed: (1) based on a $V_{\max }$ at maximum obtainable energy, (2) based on the most probable $V_{\max }$, and (3) by direct searching $V_{\text {set }}$.

\subsection{1. nMPPO design based on $V_{\text {max }}$ at maximum obtainable energy}

Fig. 6 indicates that the distribution of occurrence frequency $N_{\mathrm{s}}$ of $S$ varies at different locations. Using Figs. 5 and 6, we can calculate the accumulated power generation $E_{\mathrm{a}}(S)$ using Eq. (3) from a PV module operated at a given solar radiation intensity $S$ and at a corresponding maximum-power point (MPP), over certain period of time with hourly-mean meteorological data.

$E_{\mathrm{a}}(S)=P_{\max }(S) \times N_{\mathrm{s}} \times 1 \mathrm{~h}$, where $E_{\mathrm{a}}(S)$ is the accumulated power generation at $S$; $P_{\text {max }}(S)$ is the MPP power generation of PV module at $S$, according to Fig. $5 ; N_{\mathrm{s}}$ is the occurrence frequency of $S$.

The integral of the $E_{\mathrm{a}}$ curve over $S$ is the maximum total power generated by the PV module over certain period of time. That is,

$E_{\mathrm{tot}}=\int_{0}^{\infty} E_{\mathrm{a}}(S) \mathrm{d} S$,

$P_{\text {max }}(S)$ as well as $E_{\mathrm{a}}(S)$ represents the power output of a PV module in use with an ideal MPPT device. Hence, $E_{\text {tot }}$ can be treated as the baseline for nMPPO to compare the performance. The tracking behavior of an ideal MPPT makes the PV module operate at the maximumpower point all the time. In an nMPPO, a fixed operating voltage is used. Thus, an optimal voltage has to be determined.

If the voltage of the nMPPO is fixed at $V_{\text {set, }}$, we can define the total nMPPO efficiency for the specific duration as the ratio of actual accumulated power generation to the power generation operating at MPP all the time, in discrete form:

$\eta_{\mathrm{nMPPO}} \equiv \frac{\sum_{i=1}^{\infty}\left[P_{V_{\mathrm{pv}}}\left(S_{i}\right)-I_{\mathrm{pv}}\left(S_{i}\right) \times V_{\text {diode }}\right] \times 1 \mathrm{~h}}{\sum_{i=1}^{\infty} E_{\mathrm{a}}\left(S_{i}\right)}$

or define the nMPPO loss as

$\varepsilon_{\mathrm{nMPPO}} \equiv 1-\eta_{\mathrm{nMPPO}}$, 

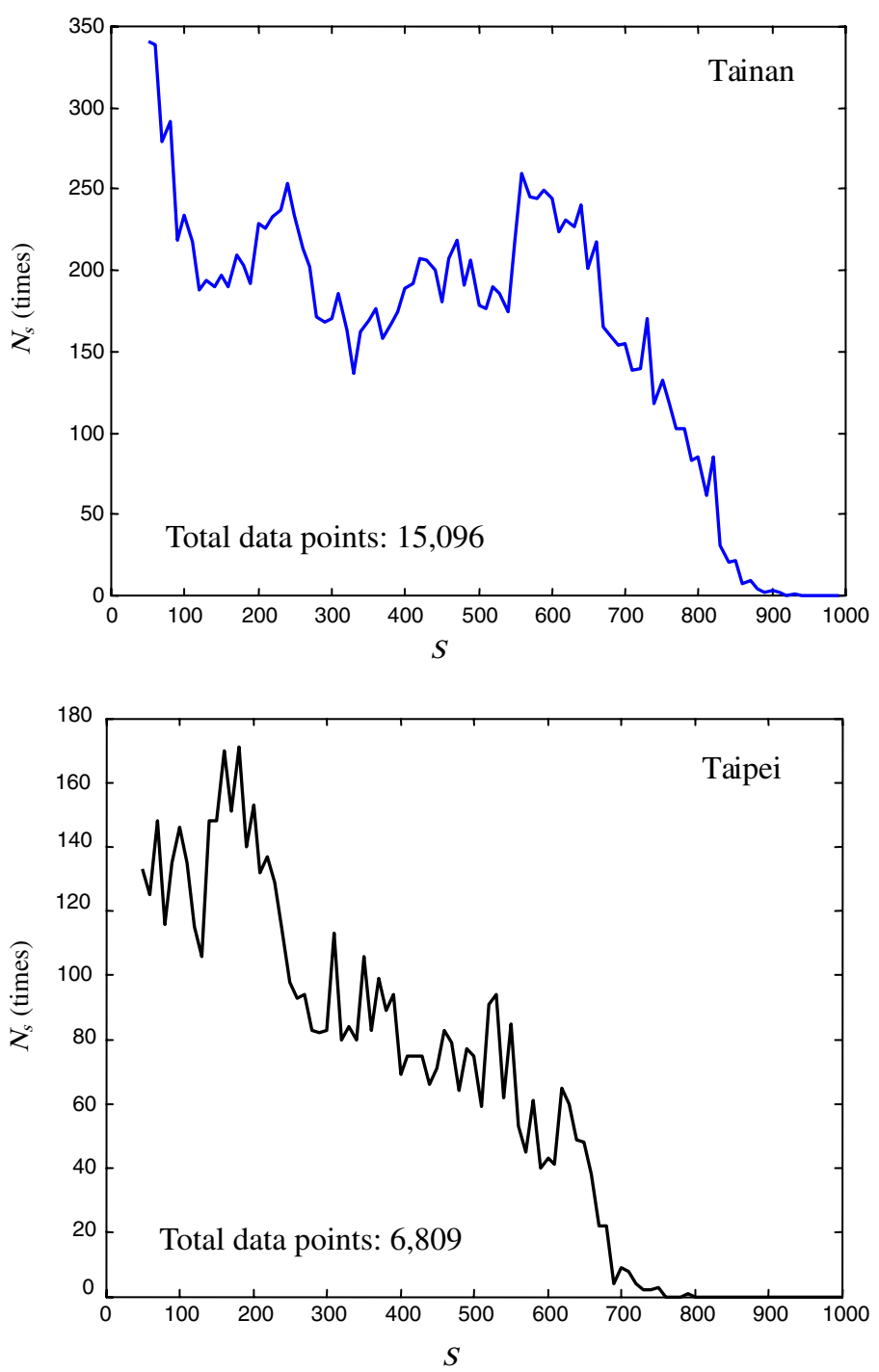

Fig. 6. Occurrence frequency of solar radiation intensity in Tainan and Taipei areas.

where

$V_{\mathrm{pv}}=V_{\text {set }}+V_{\text {diode }}$,

$I_{\mathrm{pv}}=I_{\mathrm{set}}+I_{\mathrm{load}}$,

where $P_{V_{\mathrm{pv}}}\left(S_{i}\right)$ is the power generation at $S_{i}$ in use with nMPPO; $V_{\text {diode }}$ is the voltage loss of the blocking diode (Fig. 3); $I_{\mathrm{pv}}\left(S_{i}\right)$ is the current through PV module at $V_{\text {set }}$ and $S_{i}$.

Fig. 7 shows that, $E_{\mathrm{a}}$ has a maximum value at $S=640 \mathrm{~W} / \mathrm{m}^{2}$ in Tainan area and at $S=530 \mathrm{~W} / \mathrm{m}^{2}$ in Taipei area. The value of $S$ with maximum $E_{\mathrm{a}}$ is denoted as $S_{\mathrm{E}}$. For a given $S_{\mathrm{E}}$, there exists an MPP voltage of the PV module, $V_{\mathrm{E}}$, according to Fig. 5. Table 2 lists the value of $V_{\mathrm{E}}$ at different $S_{\mathrm{E}}$.
If the voltage $V_{\text {set }}$ of the nMPPO is fixed at $V_{\mathrm{E}}$, i.e. $V_{\mathrm{set}}=V_{\mathrm{E}}$, we can calculate the nMPPO efficiency according to Eq. (5). It can be seen from Table 2 that the nMPPO efficiency is around 95\% for $V_{\text {diode }}=0.7 \mathrm{~V}$. This is very close or even better than that of the actual MPPT since the ideal MPPT is hardly obtained. It is interesting to note that $V_{\mathrm{E}}$ at various $T_{\mathrm{pv}}$ falls in a narrow range (13.2-14.5 V) and $V_{\mathrm{E}}$ are almost identical for Tainan and Taipei areas at various $T_{\mathrm{pv}}$.

\subsection{2. nMPPO design based on the most probable $V_{\max }$}

It can be seen from Figs. 4 and 5 that there exists a $V_{\max }$ as well as $P_{\max }$ at a $S$. Hence, the occurrence fre- 

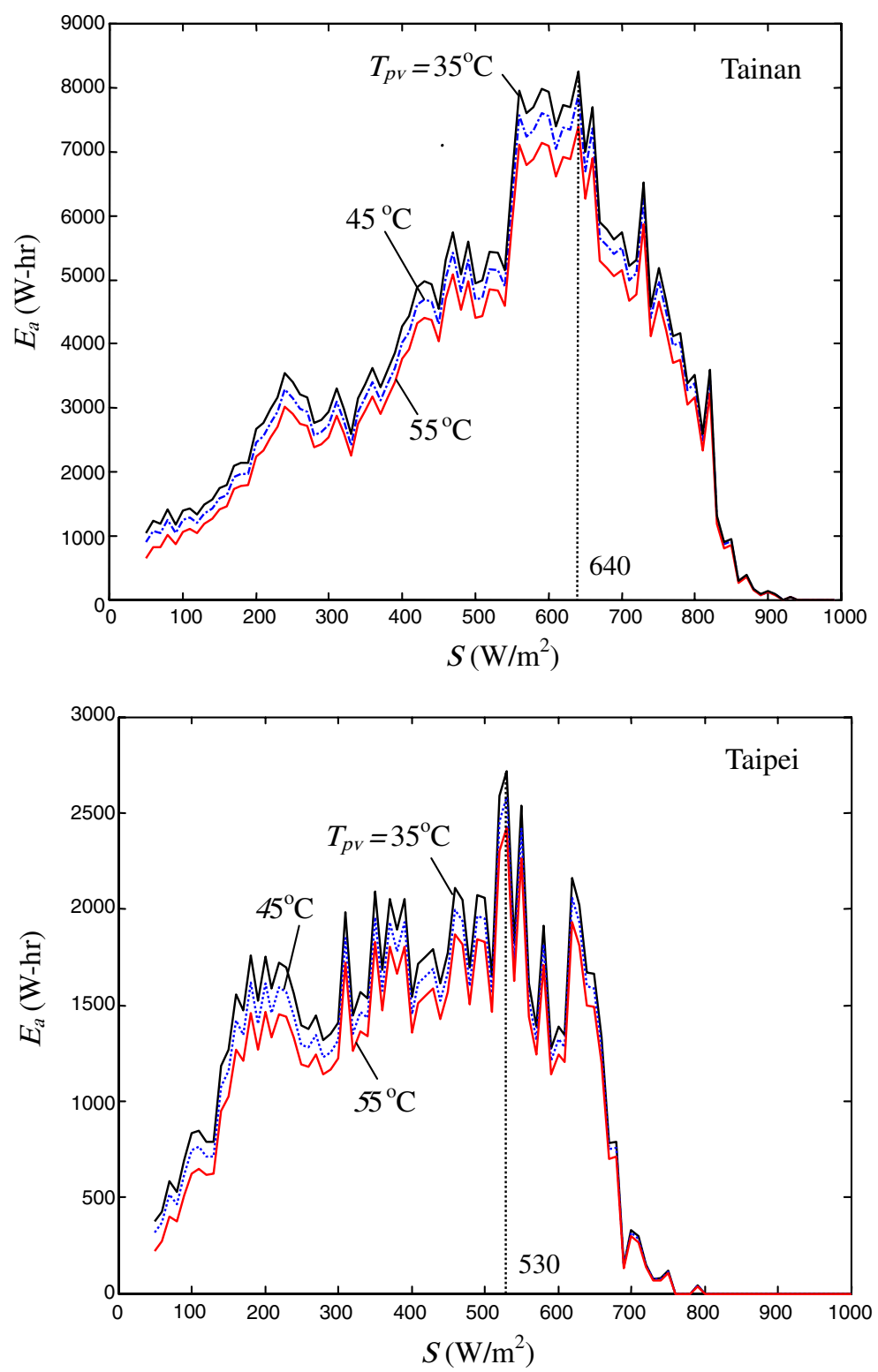

Fig. 7. Accumulated power generation at different $S$.

quency or probability function $p_{\mathrm{v}}$ of $V_{\max }$ can be defined and calculated using Eq. (9) and the meteorological data:

$p_{\mathrm{v}}\left(V_{\max }\right)=\frac{N_{\mathrm{v}}\left(V_{\max }\right)}{\int_{0}^{\infty} N_{\mathrm{v}}\left(V_{\max }\right) \mathrm{d} V_{\max }}$,

where $N_{\mathrm{v}}$ is the number of occurrence of $V_{\max }$ at certain period of time. Fig. 8 indicates that the most probable value $\left(V_{\mathrm{mp}}\right)$ of $V_{\max }$ is $14.2 \mathrm{~V}$ in both Tainan and Taipei areas at $T_{\mathrm{pv}}=45^{\circ} \mathrm{C}$. The number of occurrence of
Table 2

nMPPO efficiency at $V_{\text {set }}=V_{\mathrm{E}}$

\begin{tabular}{lllll}
\hline$T_{\mathrm{pv}}\left({ }^{\circ} \mathrm{C}\right)$ & $S_{\mathrm{E}}\left(\mathrm{W} / \mathrm{m}^{2}\right)$ & $V_{\mathrm{E}}(\mathrm{V})$ & $\eta_{\mathrm{nMPPO}}(\%)$ & $\varepsilon_{\mathrm{nMPPO}}(\%)$ \\
\hline \multicolumn{2}{l}{ Tainan } \\
35 & 640 & & & \\
45 & 640 & 14.2 & 94.42 & 5.58 \\
55 & 640 & 13.7 & 94.57 & 5.43 \\
55 & 13.2 & 94.18 & 5.82 \\
\multicolumn{2}{l}{ Taipei area $\left(V_{\text {set }}=V_{\mathrm{E}}\right)$} & & & \\
35 & 530 & 14.5 & 94.77 & 5.23 \\
45 & 530 & 13.9 & 94.78 & 5.22 \\
55 & 530 & 13.4 & 94.41 & 5.59 \\
\hline
\end{tabular}



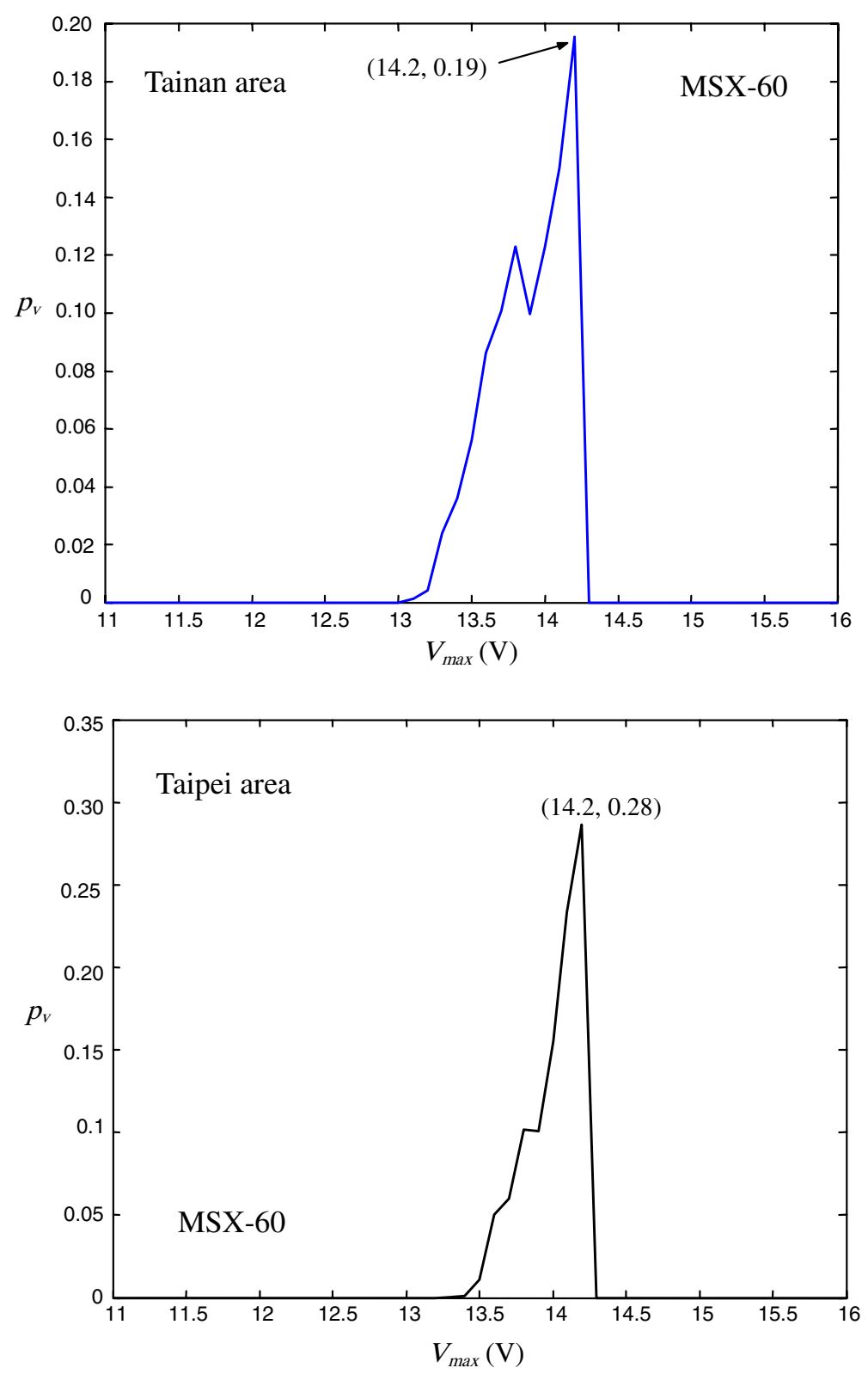

Fig. 8. Probability function $p_{\mathrm{v}}$ vs $V_{\max }\left(T_{\mathrm{pv}}=45^{\circ} \mathrm{C}\right)$.

$V_{\max }=14.2 \mathrm{~V}$ in Tainan area is 2951 out of 15,096 total data points, i.e. the probability of $V_{\max }=14.2 \mathrm{~V}$ is $19.5 \%$.

The nMPPO efficiency based on the most probable value $\left(V_{\mathrm{mp}}\right)$ of $V_{\max }$ is calculated and presented in Table 3 . It can be seen from Table 3 that the nMPPO efficiency for the specific duration is around $94 \%$ for $V_{\text {diode }}=0.7 \mathrm{~V}$. This is very close to the result of the aforementioned first design method. It is interesting to note that the values of $V_{\text {set }}\left(=V_{\mathrm{mp}}\right)$ at various $T_{\mathrm{pv}}$ are identical in Tainan and Taipei areas and falls in a narrow range (13.8-15.0 V).

\subsection{3. $n M P P O$ design by direct searching $V_{\text {set }}$}

Another nMPPO design is by a direct searching method to determine the optimal $V_{\text {set }}$. For a $T_{\mathrm{pv}}$, giving a value of $V_{\text {set, }}$ we can calculate the nMPPO efficiency $\eta_{\mathrm{nMPPO}}$ according to Eq. (5) using the meteorological data $S$. An optimum set voltage $V_{\mathrm{g}}$ can thus be obtained as shown in Table 4 . The results listed in 
Table 3

Performance of nMPPO based on the most probable $V_{\max }$

\begin{tabular}{lcll}
\hline$T_{\mathrm{pv}}\left({ }^{\circ} \mathrm{C}\right)$ & $V_{\mathrm{mp}}(\mathrm{V})$ & $\eta_{\mathrm{nMPPO}}(\%)$ & $\varepsilon_{\mathrm{nMPOO}}(\%)$ \\
\hline Tainan area $\left(V_{\text {set }}=V_{\mathrm{mp}}\right)$ & & \\
35 & 15.0 & 93.71 & 6.29 \\
45 & 14.2 & 94.26 & 5.74 \\
55 & 13.8 & 93.77 & 6.23 \\
\multicolumn{2}{l}{ Taipei area $\left(V_{\text {set }}=V_{\mathrm{mp}}\right)$} & & \\
35 & 15.0 & 94.47 & 5.33 \\
45 & 14.2 & 94.76 & 5.24 \\
55 & 13.8 & 94.49 & 5.51 \\
\hline
\end{tabular}

Table 4

Performance of nMPPO based on a $V_{\text {set }}\left(=V_{\mathrm{g}}\right)$ obtained from the direct searching method

\begin{tabular}{|c|c|c|c|}
\hline$T_{\mathrm{pv}}$ & $V_{\mathrm{g}}(\mathrm{V})$ & $\eta_{\text {nMPPO }}(\%)$ & $\varepsilon_{\mathrm{nMPPO}}(\%)$ \\
\hline \multicolumn{4}{|c|}{ Tainan area $\left(V_{\mathrm{set}}=V_{\mathrm{g}}\right)$} \\
\hline 35 & 14.5 & 94.68 & 5.32 \\
\hline 45 & 14.0 & 94.63 & 5.37 \\
\hline 55 & 13.5 & 94.33 & 5.67 \\
\hline \multicolumn{4}{|c|}{ Taipei area $\left(V_{\mathrm{set}}=V_{\mathrm{g}}\right)$} \\
\hline 35 & 14.5 & 94.77 & 5.23 \\
\hline 45 & 14.0 & 94.86 & 5.14 \\
\hline 55 & 13.5 & 94.55 & 5.45 \\
\hline
\end{tabular}

Table 4 show that the nMPPO efficiency $\eta_{\text {nMPPO }}$ for $V_{\text {set }}=V_{\mathrm{g}}$ is around $95 \%$ for $V_{\text {diode }}=0.7 \mathrm{~V}$. Fig. 9 shows the variation of power generation loss (compared to an ideal MPPT) with $V_{\mathrm{g}}$. It is noticeable that $V_{\mathrm{g}}$ at various $T_{\mathrm{pv}}$ falls in a narrow range $(13.5-14.5 \mathrm{~V})$ and are identical in Tainan and Taipei areas.

The analytical results from the above three design methods indicate that nMPPO is feasible and $V_{\text {set }}$ falls in $13.2-15.0 \mathrm{~V}$ for MSX60 for a wide range of $T_{\mathrm{pv}}$.

\section{Experimental verification of nMPPO using a single PV module}

An experiment was carried out in the present study to verify the feasibility of nMPPO. The experimental setup is shown in Fig. 10. A Solarex MSX60 (60 Wp) was used as the PV module which is installed at a tilted angle $23^{\circ}$ facing south. The above design analysis has shown that $V_{\text {set }}$ at various $T_{\mathrm{pv}}$ falls in a narrow range $(13.2-15.0 \mathrm{~V})$. A conventional 12VDC battery is thus adopted as the voltage setup $V_{\text {set }}$ device as well as an energy storage device for $\mathrm{nMPPO}$. For battery safe operation, the voltage will vary between $11.5 \mathrm{~V}$ and $13.5 \mathrm{~V}$ depending upon the state of charge of battery. Thus, $V_{\text {set }}$ is floating instead of a fixed value, due to the battery charge and discharge control. The aforementioned analytical results indicate that $V_{\text {set }}$ will decrease with increasing $T_{\mathrm{pv}}$. For $T_{\mathrm{pv}}>45^{\circ} \mathrm{C}$, the optimum $V_{\text {set }}$ will be less than $14 \mathrm{~V}$ which is very close to the battery performance (11.5$13.5 \mathrm{~V}$ ) and the real situation of the experimental PV system as well.

A DC fan was used as the load. The voltage drop of the blocking diode is $0.7 \mathrm{~V}$. The charge and discharge of the battery is controlled by a PC. Solar radiation intensity incident upon the PV module surface $S$ is measured by a pyranometer. The output current from PV is measured by a Hall sensor. The voltages of PV module and battery are measured by a data logger (Yokogawa HR3880). The temperature of PV module is measured using T-type thermocouple. The experiment is controlled by the PC, including data acquisition, measurement, and control. The measurements are taken every $2 \mathrm{~s}$ and data are recorded in the PC for further analysis.

The purpose of the present experiment is to measure the daily nMPPO efficiency $\eta_{\mathrm{nMPPO}}$ according to Eq. (5), which can be written as

$\eta_{\mathrm{nMPPO}} \equiv \frac{\sum_{i=1}^{n}\left[P_{V_{\mathrm{pv}}}\left(S_{i}\right)-I_{\mathrm{pv}}\left(S_{i}\right) \times V_{\text {diode }}\right] \times 2 \mathrm{~s}}{\sum_{i=1}^{n} P_{\max }\left(S_{i}\right) \times 2 \mathrm{~s}}$,

where the summation can be over a sequence of data in certain period of time; $P_{\max }\left(S_{i}\right)$ is the power output of the PV module in use with an ideal MPPT device that is calculated using Eqs. (1) and (2) and the measured $S_{i}$ and $T_{\mathrm{pv}}$.

In order to distinguish the effect of $T_{\mathrm{pv}}$, the test results shown in Table 5 are calculated from the data screened from all the instantaneous data at $T_{\mathrm{pv}} \pm 2{ }^{\circ} \mathrm{C}$. It is seen that the summation of power generation at various $T_{\mathrm{pv}}$ is very close to the expected ideal power generation at MPP and the total nMPPO efficiency, $\eta_{\text {nMPPO, }}$ is $93 \%$. This is acceptable since an actual MPP tracking controller will not be perfect in tracking the MPP of the PV module and there are some energy losses in the control circuits and in the imperfect MPPT control algorithm.

Some errors may exist in the test due to the measurement errors and dynamic responses. The temperature response of the PV module is much slower than the sampling time of the measurement $(2 \mathrm{~s})$. The temperature probe used to measure $T_{\mathrm{pv}}$ is mounted on the back surface of the PV module. A delay effect from the solar cell to the back surface may exist and causes the errors in measuring the power generation $P_{V_{\mathrm{pv}}}$. Another source of error may result from Eqs. (1) and (2) used for the calculation of ideal MPP power generation at given $S$ and $T_{\mathrm{pv}}$. The formulas are subject to some errors since they are derived from an outdoor performance test. This could cause error in calculating $P_{\max }\left(S_{i}\right)$. The above 

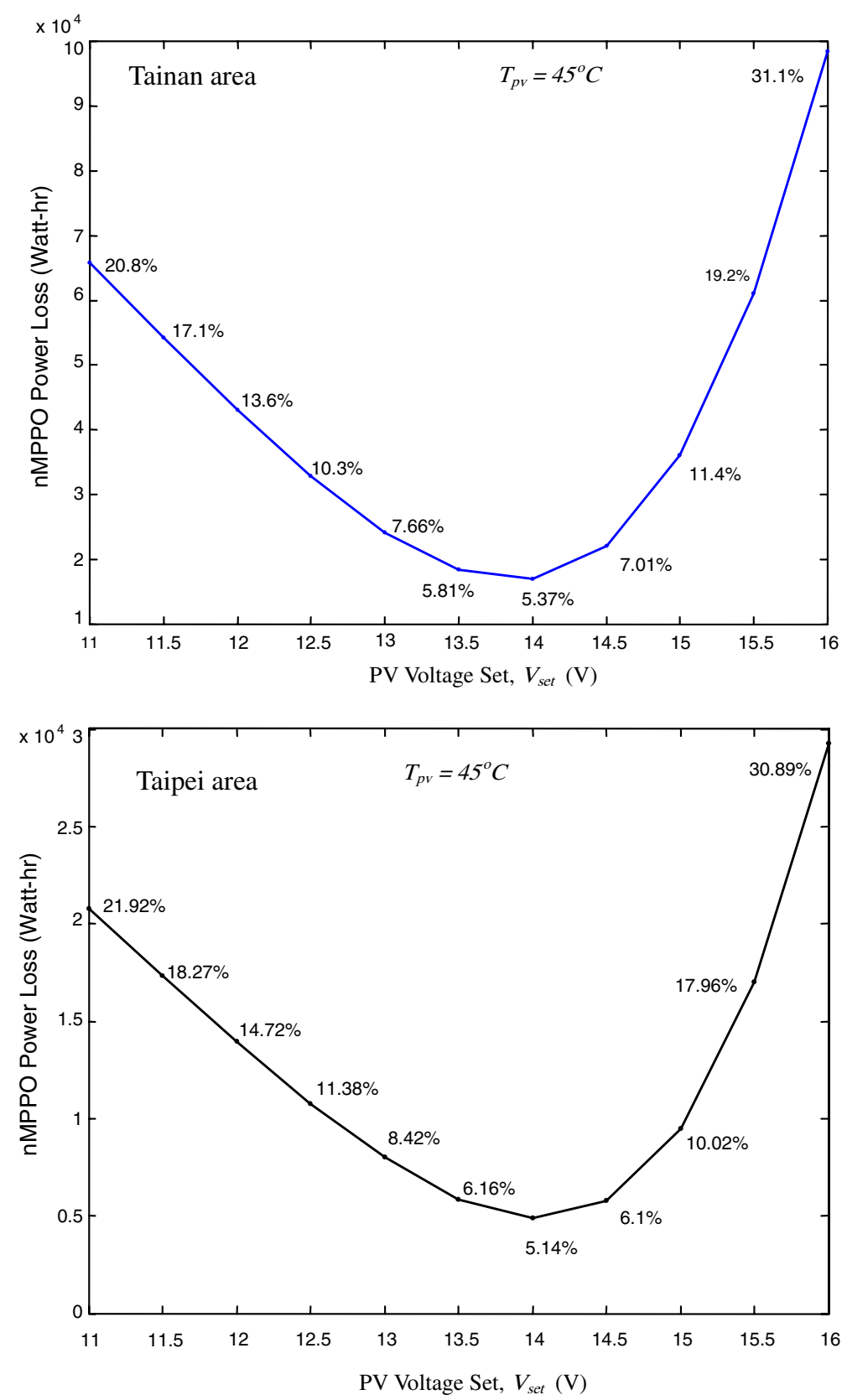

Fig. 9. nMPPO loss at various $V_{\text {set }}$.

error sources may lead to the error in the determination of $\eta_{\text {nMPPO }}$, especially at low solar radiation periods.

Fig. 11 is the instantaneous performance of $n M P P O$ at a partly-cloudy day. For further comparison, a single module PV system is tested simultaneously using another MSX60 module with a MPPT controller. The laboratory-made MPPT controller is designed based on the step-up algorithm (Salameh and Taylor, 1990). It can be seen that the power generation $P_{V_{\mathrm{pv}}}$ of the PV system with nMPPO is very close to the system with MPPT. The nMPPO keeps the PV output voltage $V_{\mathrm{pv}}$ at a nearly constant value around $12.7 \mathrm{~V}$ as compared to the tracking behavior in MPPT that has larger variation. The larger deviation of $P_{V_{\mathrm{pv}}}$ between nMPPO and MPPT at 


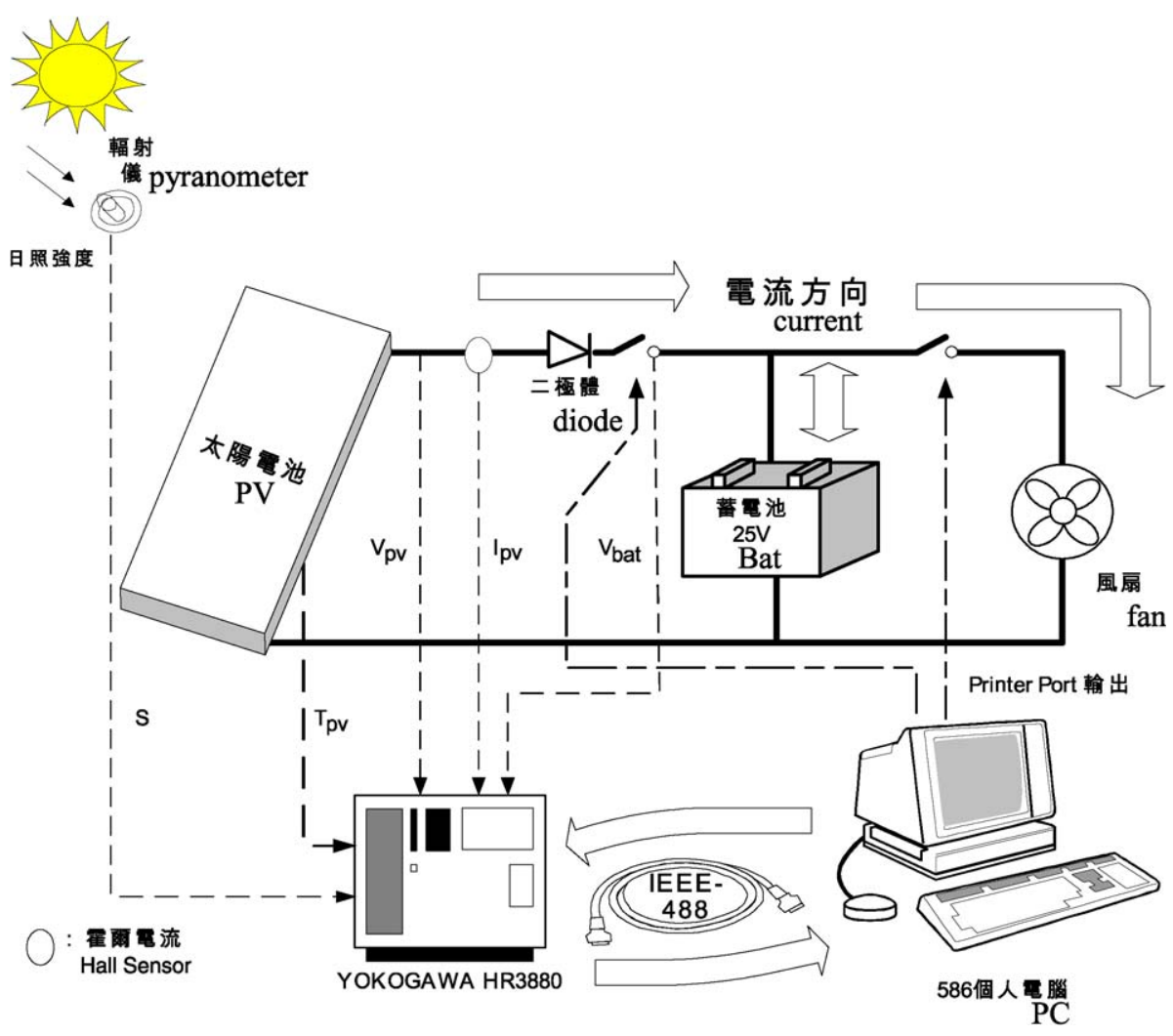

Fig. 10. Experimental setup for nMPPO test.

high radiation periods $\left(S>600 \mathrm{~W} / \mathrm{m}^{2}\right)$ is caused by the high PV temperature (around $60^{\circ} \mathrm{C}$ ). The analytical results shown in Tables 2-4 indicate that the optimum set voltage $V_{\text {set }}$ decreases with increasing $\mathrm{PV}$ temperature. Therefore, the set voltage $V_{\text {set }}$ at $12 \mathrm{~V}$ in the experiment may be too high at $T_{\mathrm{pv}}>60^{\circ} \mathrm{C}$ and causes a lower power generation as compared to MPPT. The high PV temperature obtained in the experiment also implies that the cooling of PV module is poor due to low wind speed. Actually, this condition takes place not very often in Taipei area.

At cloudy day, the test result of Fig. 12 shows that the power generation of nMPPO is almost identical with that of the MPPT. It is noted that $T_{\mathrm{pv}}$ is mostly kept below $50^{\circ} \mathrm{C}$. The set voltage $V_{\text {set }}$ at $12 \mathrm{~V}$ in the experiment is very close to the MPP. Figs. 11 and 12 also show that $P_{V_{\mathrm{pv}}}$ and $I_{\mathrm{pv}}$ in both systems are always in phase with solar radiation variation $S$.

\section{Long-term field test of nMPPO using $1 \mathrm{kWp}$ PV array}

For further verification of the nMPPO in real application, a field test using a $1 \mathrm{kWp}$ PV array was carried out. Fig. 13 shows the hardware configuration of the system. The instruments used are the same as that described previously. The $1 \mathrm{kWp}$ PV array consists of 16 MSX60 modules with 4 modules connected in series and 4 in parallel. The output power of the PV system was connected to a $48 \mathrm{~V}$ battery bank through a blocking diode. The nMPPO operation can thus be achieved via the designed battery bank voltage. To consume the power generated from the PV array when the battery is fully charged, an $800 \mathrm{~W}$-load is connected in parallel to the battery. This $800 \mathrm{~W}$ load is made of electric light bulbs for lighting.

The battery bank voltage was automatically regulated by the charge and discharge control using an energy management system based on PC. According to Table 4, the optimum $V_{\text {set }}$ will be $13.5 \mathrm{~V}$ at $T_{\mathrm{pv}}=55^{\circ} \mathrm{C}$ for a single PV module. For this field test with $4 \mathrm{PV}$ modules connected in series, $V_{\text {set }}$ will be $54 \mathrm{~V}$. Here, the battery voltage $V_{\text {load }}$ includes the voltage drop of the blocking diode, $\approx 2 \mathrm{~V}$, in the $\mathrm{PV}$ array, i.e. $V_{\text {load }}=V_{\text {diode }}+V_{\text {nMPPO }}$. The energy management system is designed to switch off the $800 \mathrm{~W}$-load for protecting the battery bank from over discharging when the battery bank voltage $V_{\text {load }}$ drops to $V_{\text {off }}=46 \mathrm{~V}$, which 
Table 5

nMPPO test results screened for different $T_{\mathrm{pv}}$

\begin{tabular}{|c|c|c|c|c|}
\hline Date & $\begin{array}{l}\text { Summation of PV } \\
\text { power generation }(\mathrm{J})\end{array}$ & $\begin{array}{l}\text { Summation of power } \\
\text { input to battery }(\mathbf{J})\end{array}$ & $\begin{array}{l}\text { Expected PV MPP } \\
\text { power generation }(\mathrm{J})\end{array}$ & $\begin{array}{l}\text { nMPPO efficiency } \\
\eta_{\text {nMPPO }}(\%)\end{array}$ \\
\hline \multicolumn{5}{|c|}{$T_{\mathrm{pv}}=55 \pm 2{ }^{\circ} \mathrm{C}$} \\
\hline $1 / 18$ & 34751.5 & 32592.4 & 34427.7 & 94 \\
\hline $1 / 19$ & 34005.7 & 31902.5 & 33714.8 & 94 \\
\hline $1 / 21$ & 1183.8 & 1125.4 & 1100.9 & 100 \\
\hline $1 / 22$ & 4186.5 & 3978.3 & 3799.3 & 100 \\
\hline $1 / 24$ & 8066.0 & 7645.3 & 7605.9 & 100 \\
\hline $1 / 31$ & 171039.8 & 159828.8 & 165118.7 & 96 \\
\hline $2 / 06$ & 92631.8 & 86469.0 & 88569.6 & 97 \\
\hline $2 / 09$ & 103889.3 & 96810.0 & 99043.3 & 97 \\
\hline $2 / 15$ & 233349.5 & 217680.6 & 245887.7 & 88 \\
\hline Total & 683,104 & 638,032 & 679,268 & 93.9 \\
\hline \multicolumn{5}{|c|}{$T_{\mathrm{pv}}=35 \pm 2{ }^{\circ} \mathrm{C}$} \\
\hline $12 / 10$ & 3433.4 & 3220.9 & 3327.5 & 96 \\
\hline $12 / 16$ & 8696.1 & 8145.2 & 9212.7 & 88 \\
\hline $12 / 18$ & 9807.8 & 9168.9 & 10546.6 & 86 \\
\hline $12 / 22$ & 15157.2 & 14167.6 & 15682.6 & 90 \\
\hline $1 / 16$ & 51409.8 & 48235.9 & 49181.9 & 98 \\
\hline $1 / 18$ & 39271.7 & 37192.1 & 36753.2 & 100 \\
\hline $1 / 19$ & 78031.6 & 74067.4 & 79570.0 & 93 \\
\hline $1 / 20$ & 71063.8 & 67544.9 & 71964.7 & 93 \\
\hline $1 / 21$ & 73965.3 & 70296.9 & 75522.4 & 93 \\
\hline $1 / 22$ & 71363.9 & 67806.8 & 73369.6 & 92 \\
\hline $1 / 24$ & 66035.8 & 62770.7 & 70731.9 & 88 \\
\hline $1 / 30$ & 6744.5 & 6276.5 & 6461.6 & 97 \\
\hline $1 / 31$ & 4893.4 & 4586.8 & 4817.0 & 95 \\
\hline $2 / 06$ & 55727.2 & 52417.2 & 57016.7 & 91 \\
\hline $2 / 08$ & 55895.7 & 52566.8 & 57175.6 & 91 \\
\hline $2 / 09$ & 66893.0 & 62520.6 & 67270.9 & 92 \\
\hline $2 / 10$ & 5378.4 & 5031.0 & 5246.6 & 95 \\
\hline $2 / 11$ & 7845.8 & 7261.8 & 7408.3 & 98 \\
\hline $2 / 15$ & 54592.3 & 51377.7 & 56085.7 & 91 \\
\hline Total & 683,104 & 704,656 & 757,346 & 93.0 \\
\hline
\end{tabular}

is the low-charge condition for the battery bank. The control system switches on the $800 \mathrm{~W}$-load when the battery bank voltage $V_{\text {load }}$ reaches $V_{\text {on }}=52 \mathrm{~V}$. When the battery bank voltage rises to over-charging voltage $V_{\text {over }}=57.6 \mathrm{~V}$, the energy management system will temporally cut off the PV connection from system to protect the battery bank from over-charging. Until the battery bank voltage drop to recover voltage $V_{\text {recover }}=56 \mathrm{~V}$, the energy management system will reconnect PV array to the battery bank. That is, during the test, each PV module will operate at a narrow voltage range (about $12-14 \mathrm{~V}$ ) that is around the MPP of the PV module. This also coincides with the analytical results of nMPPO.

The field test was monitored by a data acquisition system. The output current and voltage of the PV array, solar incident radiation, ambient temperature, PV temperature etc. are measured every 10 seconds and the time-average values are recorded every $10 \mathrm{~min}$. The daily total power generation from PV array $E_{\mathrm{nMPPO}}$ was then calculated. For comparison, the expected daily PV power generation at MPP $\left(E_{\mathrm{MPP}}\right)$ is defined as the accumulated MPP power generation if the PV is running at the MPP exactly. $E_{\mathrm{MPP}}$ is calculated using the performance equations of MSX60, Eqs. (1) and (2), and the measured PV temperature $\left(T_{\mathrm{pv}}\right)$ and solar radiation intensity $(\mathrm{S})$ in a day. $E_{\mathrm{MPP}}$ is thus an ideal power generation at MPP. The daily efficiency of nMPPO $\eta_{\mathrm{nMPPO}}$ is then defined as the ratio of the daily total power generation using nMPPO and the ideal power generation at MPP, according to Eq. (5), which can be written as 

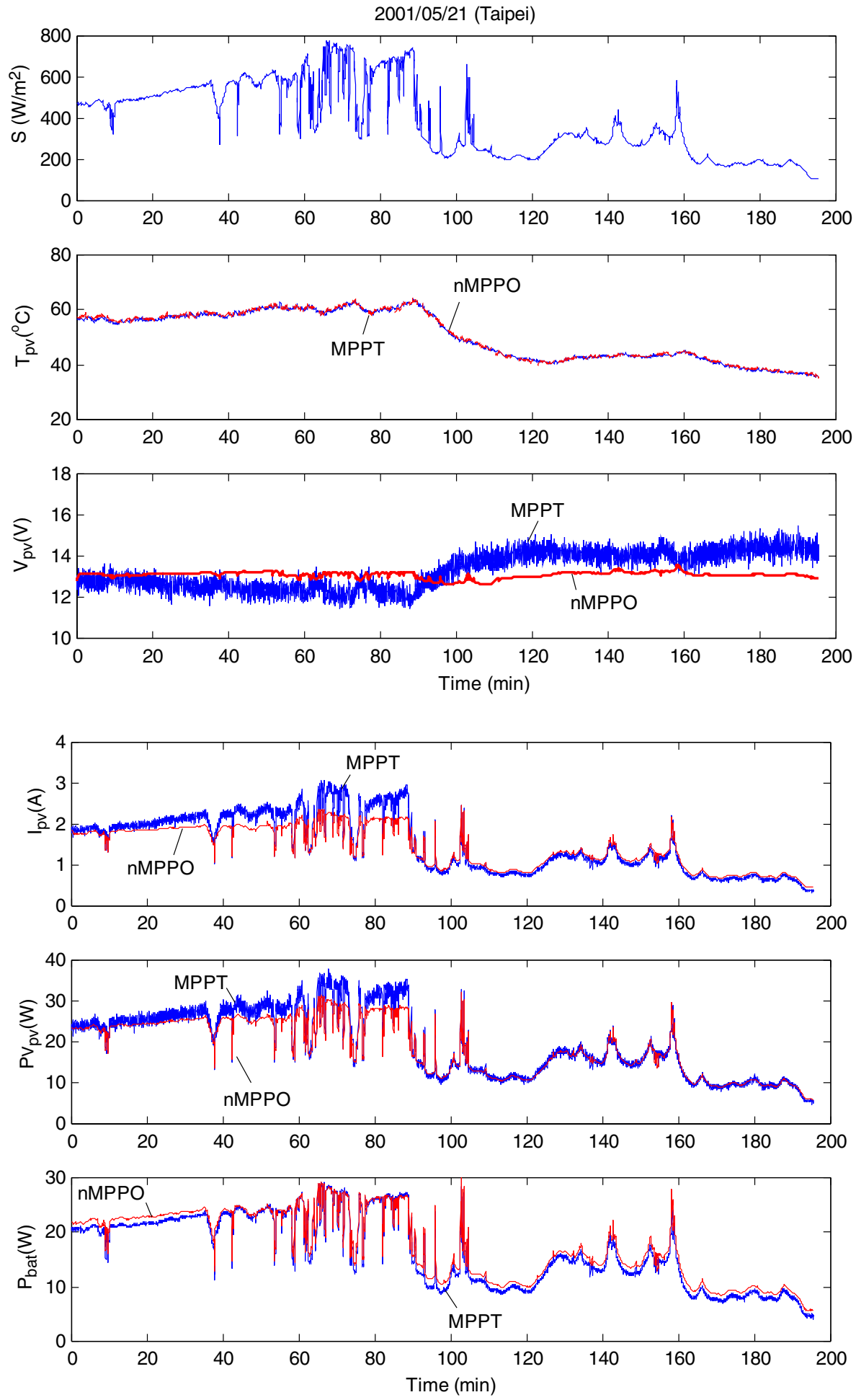

Fig. 11. Performance test of nMPPO at partly-cloudy condition. 

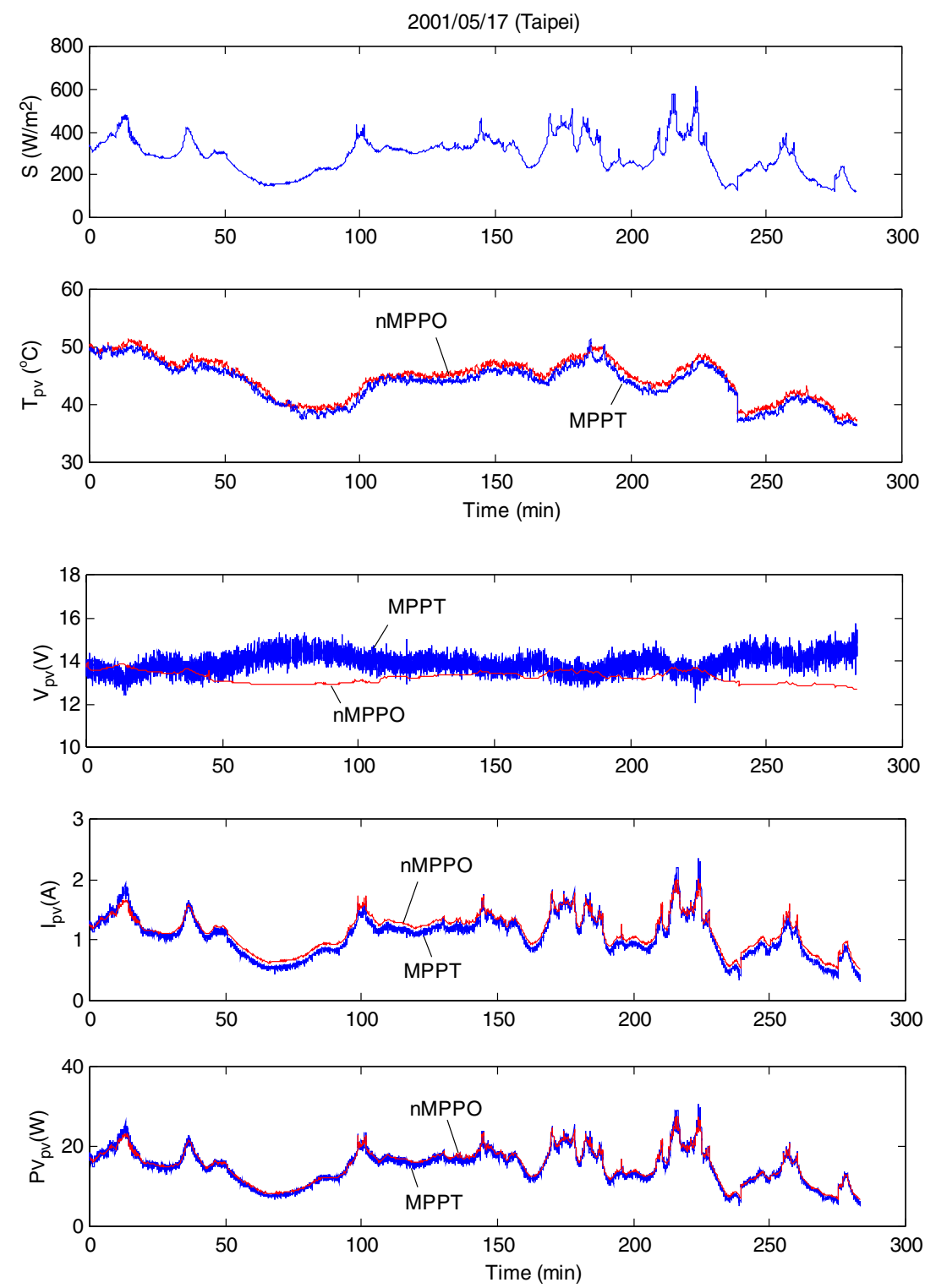

Fig. 12. Performance test of nMPPO.

$$
\begin{aligned}
\eta_{\mathrm{nMPPO}} & \equiv \frac{\sum_{i=1}^{n}\left[V_{\mathrm{pv}}\left(S_{i}\right)-V_{\text {diode }}\right] \times I_{\mathrm{pv}}\left(S_{i}\right) \times 10 \mathrm{~min}}{\sum_{i=1}^{n} P_{\max }\left(S_{i}\right) \times 10 \mathrm{~min}} \\
& =\frac{\sum_{i=1}^{n} V_{\mathrm{Batt}}(i) \times I_{\mathrm{pv}}\left(S_{i}\right) \times 10 \mathrm{~min}}{\sum_{i=1}^{n} P_{\max }\left(S_{i}\right) \times 10 \mathrm{~min}}=\frac{E_{\mathrm{nMPPO}}}{E_{\mathrm{MPP}}},
\end{aligned}
$$

Table 6 shows a list of field test data. As we can see, $E_{\mathrm{nMPPO}}$ is very close to $E_{\mathrm{MPP}}$, and $T_{\mathrm{pv}}$ varied from $24{ }^{\circ} \mathrm{C}$ to over $70{ }^{\circ} \mathrm{C}$, due to the variation of incident solar radiation and ambient temperature. The operating voltage of the nMPPO varied in an acceptable range, which is affected by the energy management system and balance of energy flow. Fig. 14 shows that the daily nMPPO efficiency, $\eta_{\mathrm{nMPPO}}$, is higher than $90 \%$ for most of the test days. Fig. 15 is the comparison of $E_{\mathrm{nMPPO}}$ and $E_{\mathrm{MPPT}}$ at various daily total solar irradiance.

The total nMPPO efficiency, $\eta_{\mathrm{o}}$, for the long-term performance is defined as

$\eta_{\mathrm{o}}=\frac{\sum E_{\mathrm{nMPPO}}}{\sum E_{\mathrm{MPP}}}$. 


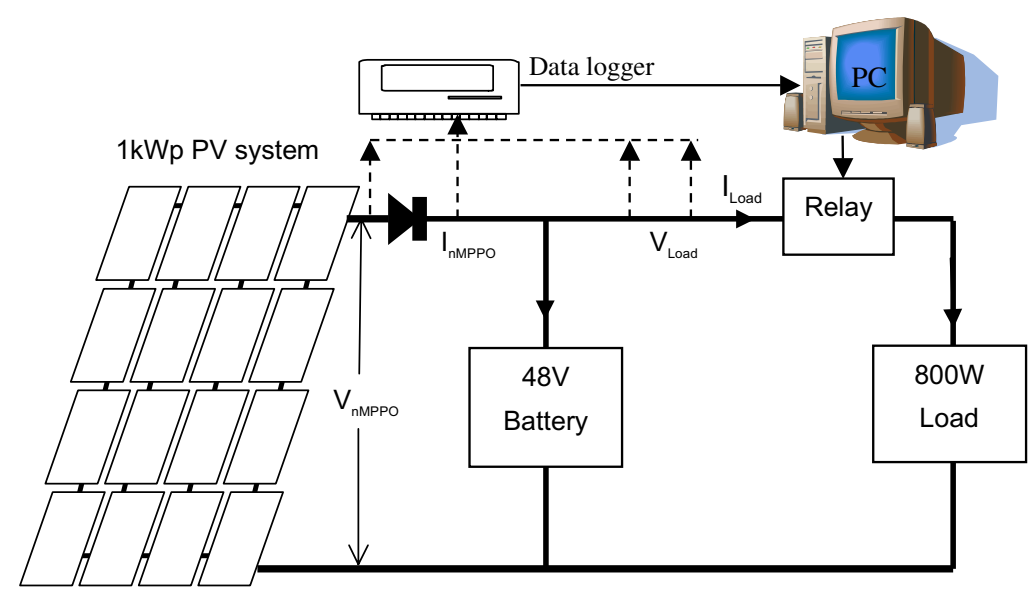

Fig. 13. Hardware configuration of the $1 \mathrm{~kW}$ PV field test system.

The field test starts from September 25, 2003 to July 12, 2004. The test results are summarized in Table 7. It indicates that the long-term total nMPPO efficiency $\eta_{\mathrm{o}}$ is over $99 \%$ as compared to the same PV array in use with an ideal MPPT at the same weather conditions. Some data in Table 6 and Fig. 15 show that the power output of nMPPO is slightly higher than that of the ideal MPPT. This is due to errors in measurement and in calculating the power output at MPP using Eqs. (1) and (2) with the measured data.

An actual MPP tracking controller conventionally available will not be perfect in tracking the MPP of the PV array since there are some energy losses due to the control circuits (hardware) and the imperfect controller algorithm (software). The present nMPPO reveals superior to the conventional MPPT control of the PV array since nMPPO can generate power very near the MPP of the PV array.

\section{Discussions and conclusion}

The present study proposes a sequence of procedure to verify the feasibility of nMPPO for local meteorology and chosen PV module and to choose optimal operating voltage range. We can implement the nMPPO by choosing battery bank very carefully with proper blocking diode, and operating the system with an energy management system. The operating voltage of nMPPO will float in a desired working range near MPP, even if PV temperature $\left(T_{\mathrm{pv}}\right)$ varied with incident solar radiation $(S)$ and ambient temperature.

The design of nMPPO that eliminates the power electronic hardware as used in MPPT has been verified analytically and experimentally in Taiwan area. Three design methods are proposed in the present study in order to determine an optimal $V_{\text {set }}$ : (1) based on a $V_{\max }$ at maximum obtainable energy, (2) based on the most probable $V_{\max }$, and (3) by direct searching $V_{\text {set. }}$. The analytical results from three design methods show that nMPPO is feasible and $V_{\text {set }}$ falls in a narrow range $13.2-15.0 \mathrm{~V}$ for MSX60 for a wide range of $T_{\mathrm{pv}}$. Both analytical and experimental results show that the efficiency of nMPPO is very close to that of MPPT

The test results for a single PV module $(60 \mathrm{Wp})$ indicate that the total nMPPO efficiency $\eta_{\mathrm{nMPPO}}$ is higher than $93 \%$ at various $T_{\mathrm{pv}}$. This is acceptable since an actual MPPT controller will not be perfect in tracking the MPP of the PV array and there are some energy losses in the control circuits and in the imperfect MPPT control algorithm.

The long-term field test of $1 \mathrm{kWp}$ PV array using nMPPO shows that the total nMPPO efficiency $\eta_{\text {nMPPO }}$ is over $99 \%$ at various weather condition and $T_{\mathrm{pv}}$ in Taipei area. As can be noticed from Table 6, during the test period, $T_{\mathrm{pv}}$ varied from $24^{\circ} \mathrm{C}$ to over $70{ }^{\circ} \mathrm{C}$, due to the variation of incident solar radiation and ambient temperature.

The energy losses of an nMPPO include the blocking diode loss and the mismatch of MPP of the PV module. The energy loss will depend on the weather conditions, including variations of solar radiation intensity and wind speed etc. The analytical results from a simulation using local meteorological data have shown that the long-term performance of nMPPO can be very close to that of MPPT. The nMPPO efficiency is higher than $94 \%$ if the battery voltage $V_{\text {set }}$ is properly designed. The design procedure of an nMPPO system is not very complicated. The performance curve of the PV module can be provided directly from the manufacturer. This can simplify the design process a great deal. 
Table 6

Long-term field test results of $1 \mathrm{Wp} \mathrm{PV}$ array with nMPPO

\begin{tabular}{|c|c|c|c|c|c|c|c|c|c|c|c|c|}
\hline \multirow[t]{2}{*}{ Test date } & \multicolumn{5}{|c|}{ nMPPO performance } & \multicolumn{7}{|c|}{ nMPPO operating condition } \\
\hline & $\begin{array}{l}\text { Total } \\
\text { incident } \\
\text { radiation, } \\
E_{\text {total }}\left(\mathrm{MJ} / \mathrm{m}^{2}\right)\end{array}$ & $\begin{array}{l}\text { Expected } \\
\text { daily ideal PV } \\
\text { power generation } \\
\text { at MPP, } E_{\mathrm{MPP}} \\
(\mathrm{kW} \text { h) }\end{array}$ & $\begin{array}{l}\text { Measured } \\
\text { daily PV power } \\
\text { generation } \\
\text { with nMPPO, } \\
E_{\text {nMPPO }}(\mathrm{kW} \mathrm{h})\end{array}$ & $\begin{array}{l}\text { PV daily } \\
\text { efficiency } \\
E_{\text {nMPPO/ }} / \\
E_{\text {total }}(\%)\end{array}$ & $\begin{array}{l}\text { nMPPO } \\
\text { daily } \\
\text { efficiency } \\
E_{\mathrm{nMPPO}} / \\
E_{\mathrm{MPP}}(\%)\end{array}$ & $\begin{array}{l}\text { Average } \\
\text { diode }(\mathrm{V})\end{array}$ & $\begin{array}{l}\text { Maximum } \\
V_{\mathrm{pv}}(\mathrm{V})\end{array}$ & $\begin{array}{l}\text { Minimum } \\
V_{\mathrm{pv}}(\mathrm{V})\end{array}$ & $\begin{array}{l}\text { Average } \\
V_{\mathrm{pv}}(\mathrm{V})\end{array}$ & $\begin{array}{l}\text { Maximum } \\
T_{\mathrm{pv}}\left({ }^{\circ} \mathrm{C}\right)\end{array}$ & $\begin{array}{l}\text { Minimum } \\
T_{\mathrm{pv}}\left({ }^{\circ} \mathrm{C}\right)\end{array}$ & $\begin{array}{l}\text { Average } \\
T_{\mathrm{pv}}\left({ }^{\circ} \mathrm{C}\right)\end{array}$ \\
\hline $2003 / 09 / 25$ & 16.38 & 3.41 & 3.37 & 9.16 & 98.9 & 1.83 & 60.1 & 49.5 & 54.3 & 65.5 & 26.0 & 49.7 \\
\hline 2003/09/26 & 4.83 & 1.17 & 1.02 & 9.10 & 87.8 & 1.57 & 53.5 & 50.2 & 52.4 & 42.6 & 26.1 & 32.6 \\
\hline 2003/09/27 & 9.21 & 2.09 & 1.86 & 8.82 & 89.1 & 1.77 & 53.5 & 47.7 & 50.8 & 53.6 & 26.9 & 40.8 \\
\hline $2003 / 09 / 28$ & 22.71 & 4.55 & 4.75 & 9.37 & 104.4 & 1.70 & 55.1 & 49.8 & 53.0 & 69.0 & 24.1 & 53.7 \\
\hline 2003/09/29 & 22.00 & 4.45 & 4.59 & 9.35 & 103.1 & 1.74 & 55.4 & 50.2 & 53.1 & 68.0 & 25.4 & 53.2 \\
\hline 2003/09/30 & 22.50 & 4.50 & 4.66 & 9.28 & 103.4 & 1.78 & 55.5 & 50.1 & 53.2 & 69.0 & 24.8 & 54.8 \\
\hline 2003/10/01 & 17.67 & 3.66 & 3.53 & 8.95 & 96.4 & 1.72 & 53.8 & 48.2 & 51.5 & 72.3 & 24.4 & 51.6 \\
\hline 2003/10/02 & 19.11 & 3.97 & 3.87 & 9.08 & 97.6 & 1.78 & 54.6 & 48.3 & 52.0 & 68.3 & 25.9 & 51.1 \\
\hline $2003 / 10 / 03$ & 19.26 & 3.95 & 3.95 & 9.21 & 100.0 & 1.91 & 55.3 & 48.0 & 52.5 & 66.9 & 26.7 & 51.5 \\
\hline 2003/10/04 & 2.76 & 0.60 & 0.57 & 7.84 & 95.0 & 1.96 & 55.1 & 48.3 & 52.4 & 39.2 & 24.3 & 29.0 \\
\hline 2003/10/05 & 13.00 & 2.89 & 2.69 & 9.17 & 93.0 & 1.89 & 53.5 & 48.4 & 51.1 & 60.0 & 26.9 & 41.6 \\
\hline 2003/10/06 & 8.16 & 1.96 & 1.72 & 9.29 & 87.9 & 2.02 & 53.5 & 48.5 & 51.3 & 56.3 & 26.2 & 34.3 \\
\hline 2003/10/07 & 3.67 & 0.89 & 0.77 & 8.67 & 86.1 & 1.98 & 53.2 & 49.1 & 52.0 & 35.8 & 25.1 & 30.1 \\
\hline 2003/10/08 & 8.89 & 2.00 & 1.82 & 8.97 & 90.6 & 2.30 & 56.8 & 48.9 & 51.9 & 59.0 & 28.8 & 40.5 \\
\hline 2003/10/09 & 11.31 & 2.52 & 2.28 & 8.87 & 90.6 & 2.02 & 53.8 & 48.5 & 51.3 & 60.4 & 25.6 & 43.7 \\
\hline 2003/10/10 & 21.87 & 4.37 & 4.53 & 9.26 & 103.5 & 2.20 & 56.4 & 49.2 & 53.7 & 68.5 & 26.8 & 55.8 \\
\hline 2003/10/11 & 17.45 & 3.44 & 3.49 & 8.91 & 101.5 & 2.18 & 56.3 & 49.2 & 53.4 & 69.9 & 27.6 & 52.9 \\
\hline 2003/10/12 & 15.48 & 3.28 & 3.09 & 8.93 & 94.3 & 2.07 & 54.4 & 49.2 & 52.0 & 67.9 & 25.4 & 49.7 \\
\hline 2003/10/13 & 8.69 & 1.86 & 1.76 & 8.88 & 94.7 & 1.86 & 53.9 & 48.7 & 51.7 & 64.0 & 28.0 & 45.8 \\
\hline 2003/10/14 & 2.43 & 0.53 & 0.54 & 8.01 & 100.8 & 1.59 & 53.5 & 49.3 & 52.0 & 30.3 & 24.4 & 27.0 \\
\hline 2003/10/15 & 1.83 & 0.43 & 0.40 & 8.21 & 92.6 & 1.61 & 53.3 & 49.0 & 52.5 & 29.2 & 22.5 & 25.2 \\
\hline $2003 / 10 / 16$ & 11.72 & 2.81 & 2.40 & 9.07 & 85.2 & 2.12 & 59.0 & 47.9 & 51.4 & 45.8 & 22.3 & 36.9 \\
\hline 2003/10/17 & 17.51 & 3.72 & 3.63 & 9.26 & 97.6 & 1.89 & 56.4 & 47.8 & 52.7 & 67.2 & 21.3 & 46.0 \\
\hline 2003/10/18 & 17.71 & 3.83 & 3.70 & 9.33 & 96.6 & 1.99 & 54.7 & 47.5 & 51.7 & 60.2 & 20.5 & 44.7 \\
\hline $2003 / 10 / 19$ & 14.04 & 3.11 & 2.91 & 9.22 & 93.5 & 1.95 & 55.8 & 49.3 & 52.3 & 59.6 & 25.1 & 43.3 \\
\hline $2003 / 10 / 20$ & 18.48 & 3.92 & 3.77 & 9.10 & 96.0 & 2.11 & 56.3 & 48.1 & 52.4 & 64.9 & 22.3 & 47.0 \\
\hline $2003 / 10 / 21$ & 17.88 & 3.82 & 3.73 & 9.31 & 97.5 & 2.08 & 57.7 & 48.7 & 53.2 & 60.5 & 23.8 & 45.9 \\
\hline $2003 / 10 / 22$ & 17.55 & 3.77 & 3.55 & 9.02 & 94.2 & 2.40 & 56.1 & 48.3 & 52.5 & 61.8 & 18.5 & 46.1 \\
\hline $2003 / 10 / 23$ & 7.30 & 1.60 & 1.50 & 8.77 & 93.9 & 2.03 & 55.1 & 48.8 & 52.3 & 63.3 & 19.7 & 35.5 \\
\hline $2003 / 10 / 24$ & 20.91 & 4.31 & 4.37 & 9.33 & 101.2 & 2.09 & 59.6 & 48.6 & 54.2 & 65.2 & 18.2 & 48.7 \\
\hline $2003 / 10 / 25$ & 22.63 & 4.61 & 4.70 & 9.30 & 102.0 & 2.03 & 60.5 & 48.3 & 54.9 & 65.6 & 15.2 & 50.2 \\
\hline $2003 / 10 / 26$ & 20.60 & 4.33 & 4.31 & 9.37 & 99.5 & 1.95 & 58.7 & 48.0 & 53.3 & 63.6 & 18.0 & 48.7 \\
\hline $2003 / 10 / 27$ & 17.04 & 3.56 & 3.39 & 8.85 & 95.1 & 2.02 & 55.1 & 48.3 & 52.0 & 66.8 & 20.4 & 49.1 \\
\hline $2003 / 10 / 28$ & 20.32 & 4.20 & 4.16 & 9.16 & 99.1 & 2.02 & 58.0 & 48.3 & 53.3 & 66.1 & 19.0 & 50.3 \\
\hline $2003 / 10 / 29$ & 18.63 & 3.99 & 3.74 & 8.99 & 93.8 & 2.72 & 58.9 & 47.9 & 53.9 & 60.8 & 24.6 & 47.9 \\
\hline Total & 511.53 & 108.10 & 105.12 & 9.01 & 97.2 & 1.97 & 55.8 & 48.7 & 52.5 & 59.6 & 23.7 & 44.4 \\
\hline
\end{tabular}




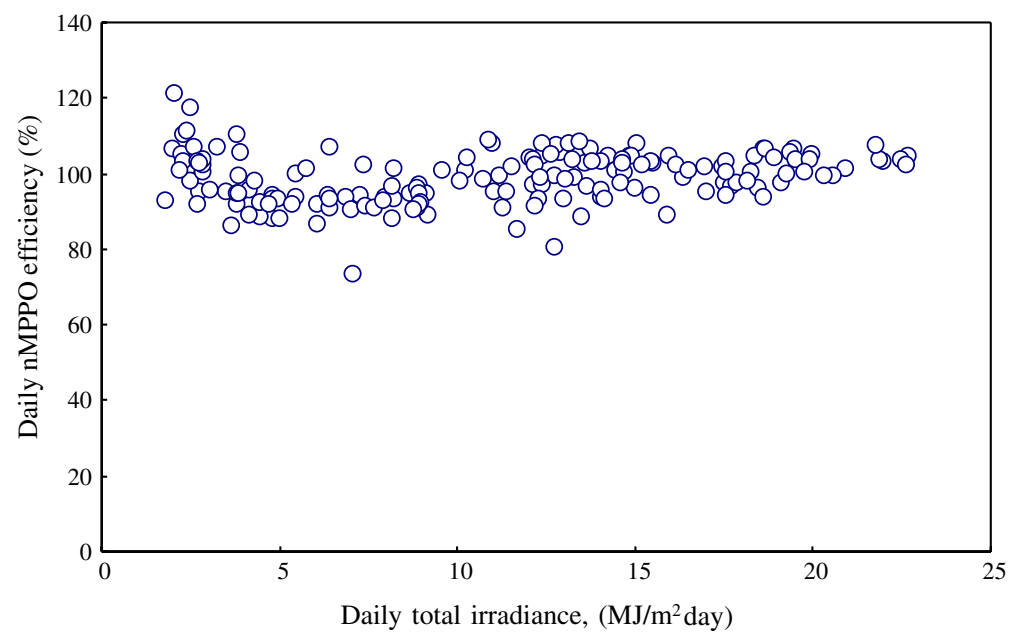

Fig. 14. Daily nMPPO efficiency.

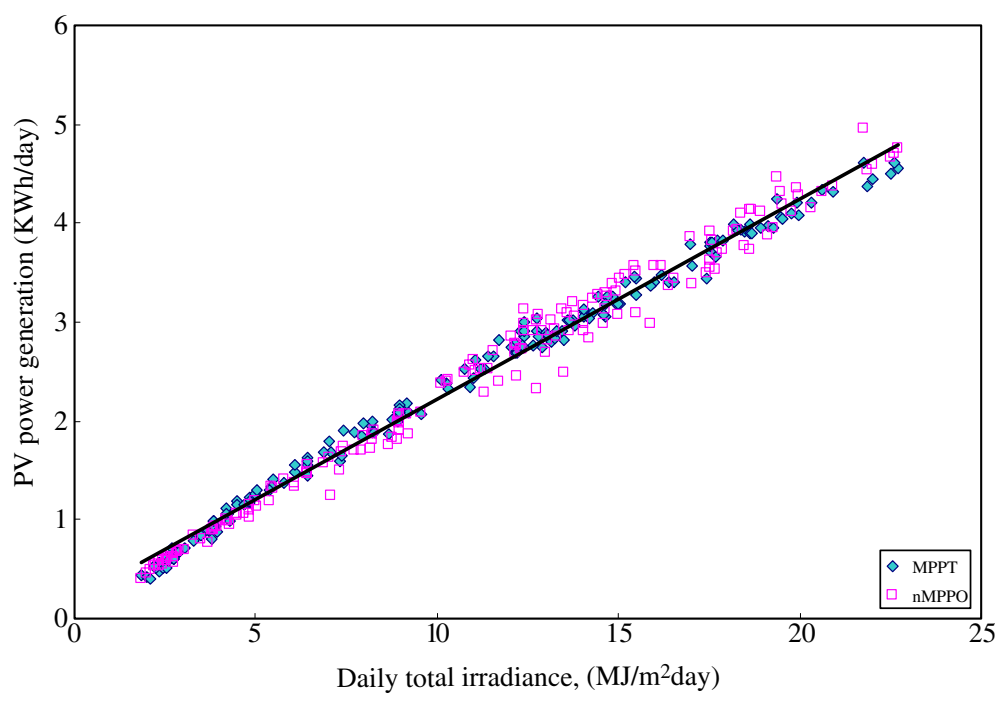

Fig. 15. Daily power output comparison for nMPPO and MPPT.

Table 7

Long-term field test results of $1 \mathrm{kWp}$ PV array with nMPPO (2003/9/25-2004/7/12)

\begin{tabular}{llll}
\hline $\begin{array}{l}\text { Total incident solar } \\
\text { radiation }\left(\mathrm{MJ} / \mathrm{m}^{2}\right)\end{array}$ & $\begin{array}{l}\text { Total power generation } \\
\text { with ideal MPPT }(\mathrm{kW} \mathrm{h})\end{array}$ & $\begin{array}{l}\text { Total power generation } \\
\text { with nMPPO }(\mathrm{kW} \mathrm{h})\end{array}$ & nMPPO efficiency $(\%)$ \\
\hline 1883.13 & 415.01 & 411.65 & 99.2 \\
\hline
\end{tabular}

Nevertheless, the design procedure of nMPPO can be further standardized for application in various areas. The nMPPO is a reliable and economical design that can be adopted in many PV systems. The battery used in the nMPPO has dual functions, i.e., voltage control and energy storage. For a grid-connected system, the method of nMPPO design is still applicable in the design of PV operating voltage. 
The present study used a $60 \mathrm{Wp}$ and a $1 \mathrm{kWp}$ system to verify the design concept of nMPPO. Both give a satisfactory result.

\section{Acknowledgement}

The present study is supported by Energy Commission, Ministry of Economic Affairs, Taiwan.

\section{References}

Salameh, Z., Taylor, D., 1990. Step-up maximum power point tracker for photovoltaic arrays. Solar Energy 44 (1), 57-61.

Salameh, Z., Dagher, F., Lynch, W.A., 1991. Step-down maximum power point tracker for photovoltaic system. Solar Energy 46 (1), 278-282. 